\title{
ОЦЕНКА СОРТООБРАЗЦОВ КРАМБЕ В ЗАВИСИМОСТИ ОТ ГИДРОТЕРМАЛЬНЫХ УСЛОВИЙ
}

Т. Я. Прахова, доктор с.-х. наук, гл. науч. сотрудник, Е. Л. Турина*, канд. с.-х. наук, зав. лабораторией растениеводства

Федеральное государственное бюджетное научное учреждение «Федеральный научный центр лубяных культур», Россия, р. п. Лунино, т. +79534479608, e-mail: prakhova.tanya@yandex.ru;

*Федеральное государственное бюджетное учреждение науки «Научно-исследовательский институт сельского хозяйства Крыма», Россия, г. Симферополь, Республика Крым, T. +79788741692, e-mail: turina_e@niishk.ru

Целью исследований являлась оценка сортообразцов крамбе абиссинской по продуктивности и адаптивности в зависимости от гидротермальных условий. Объектом исследований являлись сортообразцы различного эколого-географического происхождения. Изучение проводилось в контрастных климатических условиях Среднего Поволжья и степного Крыма в 2017-2019 годах. Продуктивность сортообразцов крамбе абиссинской варьирует в пределах 1,54-2,04 т/га, в среднем по двум регионам. В среднем за три года более высокий урожай отмечен у образцов к-39 (США) и к-35 (Германия), продуктивность которых составила 2,01-2,04 т/га, что превышает сорт-стандарт Деметра на 0,22 и 0,25 т/га. Данные номера отличались высокими значениями коэффрициента адаптивности, который составил 1,04-1,13 и показывает их большую приспособленность к различным условиям возделывания. Сортообразцы из Канады (к-25) и из Чехословакии (к-34) сфоормировали урожайность 1,82 и 1,87 т/га, что несущественно превышает стандарт по урожайности. Прибавка здесь составила 0,03 и 0,08 т/га. Содержание жира в плодиках колебалась в пределах 29,68-32,20 \%. По результатам данного признака выделился номер из Германии к-35, масличность которого составила 32,20 \%. Наиболее стабильными по урожайности были образцы к-35, к-34 и к-10, параметры стабильности которых составили 22,8; 26,1 и 29,0 \%. Высоким значением показателя уровня стабильности сорта (ПУСС) отличались сортообразцы к-39 и к-10, значения данного признака составили 0,47 и 0,52 соответственно. При этом у данных номеров отмечена высокая экологическая устойчивость $(0,49$ и 0,53$)$, что показывает более широкий диапазон их приспособленности к различным условиям произрастания.

Ключевые слова: крамбе абиссинская, сортообразцы, урожайность, адаптивность, масличность.

\section{Введение.}

Возделывание набора культур и сортов, которые в наибольшей степени приспособлены к местным, в том числе и экстремальным, условиям внешней среды, является главным фрактором реализации биоклиматического потенциала каждого региона, особенно находящегося в неблагоприятных почвенно-климатических условиях. Это обеспечивает существенное расширение ассортимента сельскохозяйственных культур, наиболее приспособленных к факторам (температура, влага), лимитирующим величину и качество урожая [3].

В настоящее время, вследствие глобальных трансформаций климатических условий, имеющих тенденцию к повышению температур, поднимается вопрос расширения ассортимента масличных культур и распространения наиболее засухоустойчивых культур, способных формировать стабильные урожаи при ухудшении теплового и водного режимов [10, 14].

К таким культурам относится крамбе абиссинская (Crambe abyssinica) - нетрадиционная перспективная масличная культура семейства Brassicaceae.

Крамбе достаточно новая для российских сельхозпроизводителей агрокультура. Однако, интерес к ней в настоящее время очень большой и обусловлен как экономическими, так и агрономическими ее показателями, в качестве альтернативы традиционным масличным культурам $[5,8,11]$.

По данным многих исследователей целесообразность выращивания данной культуры обусловлена не только уникальными биологическими особенностями растения, но и высокой масличностью семян (до $45 \%$ ) с высоким содержанием в масле эруковой кислоты (до $60 \%$ ), что позволяет использовать его на технические цели и, в первую 
очередь, для получения биотоплива $[4,9$, 14, 15].

Биологические особенности крамбе позволяют выращивать ее в широком диапазоне почвенно-климатических условий. Она хорошо адаптируется к возделыванию как в регионах с высокой относительной влажностью воздуха и достаточным количеством осадков, так и с умеренными температурами в период вегетации, а также в районах с недостаточной влажностью. Крамбе неприхотлива к почвенно-климатическим условиям и наиболее полно использует агроэкологические условия региона возделывания, что обеспечивает высокий потенциал урожайности маслосемян (до 3,0 т/га) $[5,10,12,17]$.

Кроме того, крамбе является хорошими предшественником для зерновых культур, обладает сидеральными свойствами и способствует значительному снижению сорной растительности $[12,14,16]$.

Благодаря своей пластичности и толерантности к условиям возделывания в последнее время крамбе все больше приобретает популярность во многих регионах как Российской Федерации, так и за рубежом [8, 11, 16, 17].

Однако более широкое внедрение крамбе и увеличение ее посевных площадей зависят от сортового разнообразия наиболее адаптированного к условиям возделывания и проявляющим устойчивость к нерегулируемым фракторам внешней среды. В условиях производства продуктивность сельскохозяйственных культур зависит не только от агротехники, но и, в большей степени, от подбора сортов [1].

Наличие сортов крамбе абиссинской, экологически устойчивых к местным агроклиматическим условиям региона возделывания, способствует стабилизации роста урожайности культуры и, зачастую, решает судьбу ее возделывания на данной территории. Поэтому оценка сортообразцов крамбе и их адаптивность в конкретных почвенно-климатических условиях является актуальной.

Целью наших исследований являлась оценка сортообразцов крамбе абиссинской по продуктивности и адаптивности в зависимости от гидротермальных условий в контрастных агроклиматических регионах Среднего Поволжья и степного Крыма.

\section{Материалы и методы}

Объектом исследований являлись сортообразцы крамбе абиссинской различного эколого-географического происхождения. Изучение проводилось в контрастных гидротермических условиях Среднего Поволжья и степного Крыма в 2017-2019 годах.

Климат Средневолжского региона умеренно-континентальный. Сумма годовых осадков варьирует в широком диапазоне от 350 до 750 мм. Среднегодовая температура составляет $5,3^{\circ} \mathrm{C}$. Сумма температур за период с температурой $+10{ }^{\circ} \mathrm{C}$ составляет в среднем $2450{ }^{\circ} \mathrm{C}$.

Климат зоны степного Крыма континентальный, с большими годовыми и суточными колебаниями температуры. Среднегодовая температура здесь составляет $10,2^{\circ} \mathrm{C}$ при 350-450 мм осадков в год. На протяжении последних лет наблюдается тенденция её повышения. Суммы эффективных температур варьируют от 3300 до $3600{ }^{\circ} \mathrm{C}$.

Вегетационный период крамбе в 2017 году протекал в недостаточно увлажненных условиях при ГТК 0,68 единицы в Крыму и в условиях умеренного увлажнения (ГТК 0,90) в Пензенском регионе. Условия 2018 года были отмечены как острозасушливые для обоих регионов исследований, ГТК составил 0,35-0,49. Период вегетации 2019 года протекал с дефицитом осадков в Пензенской области (ГТК = 0,62) и при умеренном увлажнении (ГТК $=1,07)$ в условиях НИИСХ Крыма (табл. 1).

Наиболее стрессовые условия для роста и развития сортообразцов крамбе сложились в 2018 году как в Среднем Поволжье, так и в зоне степного Крыма. Величина индекса условий среды здесь составляет - 0,13 и - 0,89 соответственно. Наиболее оптимальные условия для роста и развития сортообразцов крамбе сложились в 2017 году, индекс условий среды составил 0,38 и 0,66 .

Оценку продуктивности сортообразцов проводили согласно существующим методическим рекомендациям по масличным культурам [6].

Индекс условий среды определяли по методике S. A. Eberhart и W. A. Russel [13].

Гидротермальные условия развития крамбе абиссинской

Таблица 1

\begin{tabular}{|l|c|c|c|c|c|c|}
\hline \multirow{2}{*}{ Показатель } & \multicolumn{2}{|c|}{2017 г. } & \multicolumn{2}{c|}{2018 г. } & \multicolumn{2}{c|}{2019 г. } \\
\cline { 2 - 7 } \multicolumn{1}{|c|}{} & Пенза & Крым & Пенза & Крым & Пенза & Крым \\
\hline Среднесуточная температура, ${ }^{\circ} \mathrm{C}$ & 17,6 & 13,9 & 18,6 & 16,0 & 17,5 & 15,2 \\
\hline Количество осадков, мм & 134,2 & 106,1 & 54,6 & 91,4 & 137,1 & 182,2 \\
\hline ГТК & 0,90 & 0,68 & 0,35 & 0,49 & 0,62 & 1,07 \\
\hline Индекс условий среды, lj & 0,38 & 0,66 & $-0,13$ & $-0,89$ & $-0,25$ & 0,24 \\
\hline
\end{tabular}


Коэффициент адаптивности сортообразцов рассчитывали согласно методике Л. А. Животкова [2]. Показатель уровня стабильности сорта (ПУСС) определяли по методике, описанной Э. Д. Неттевичем [7].

\section{Результаты исследований}

Продуктивность сортообразцов крамбе абиссинской варьирует в пределах 1,54-2,04 т/га, в среднем по двум регионам (Пенза и Крым). За три года исследований более высокий урожай отмечен у образцов к-39 (США) и к-35 (Германия), продуктивность которых составила 2,01 и 2,04 т/га, соответственно, что превышает сорт-стандарт Деметра на 0,22 и 0,25 т/га (табл. 2).

Таблича 2

Показатели продуктивности сортообразцов крамбе абиссинской (среднее по двум регионам)

\begin{tabular}{|c|c|c|c|c|}
\hline $\begin{array}{l}\text { Сорто- } \\
\text { образец }\end{array}$ & $\begin{array}{c}\text { Проис- } \\
\text { хождение }\end{array}$ & 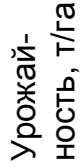 & 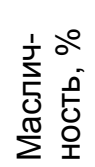 & 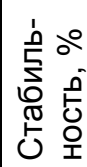 \\
\hline $\begin{array}{l}\text { Деметра, } \\
\text { st }\end{array}$ & Пенза & 1,79 & 31,45 & 17,0 \\
\hline $\mathrm{K}-25$ & Канада & 1,82 & 30,48 & 11,9 \\
\hline K-35 & Германия & 2,04 & 32,20 & 22,8 \\
\hline$\kappa-10$ & Украина & 1,79 & 31,42 & 29,0 \\
\hline$\kappa-7$ & Воронеж & 1,54 & 30,01 & 18,4 \\
\hline K-8 & Башкирия & 1,56 & 29,68 & 15,7 \\
\hline K-39 & США & 2,01 & 31,53 & 18,0 \\
\hline$\kappa-34$ & Чехословакия & 1,87 & 31,67 & 26,1 \\
\hline к-21 & Португалия & 1,79 & 30,44 & 13,0 \\
\hline $\mathrm{HCP}_{05}$ & & 0,13 & 0,23 & - \\
\hline
\end{tabular}

Сортообразцы из Канады (к-25) и из Чехословакии (к-34) сфрормировали урожайность 1,82 и 1,87 т/га, что несущественно превышает стандарт по урожайности. Прибавка здесь составила 0,03 и 0,08 т/га. Остальные образцы по семенной продуктивности не превышали сорт Деметра.

Содержание жира в плодиках колебалась в пределах 29,68-32,20 \%. По результатам данного признака выделился номер из Германии к-35, масличность которого составила 32,20 \%. Образцы к-39 и к-34 несущественно превышали по содержанию масла сорт-стандарт, прибавка здесь была в пределах наименьшей существенной разницы и составила и 0,08 и 0,22 \%.

В соответствии с условиями среды варьировала и среднесортовая урожайность сортообразцов крамбе. Варьирование урожайности по годам и по регионам составила: в Крыму - 23,45 \%; в Пензе $17,75 \%$. Это говорит о стабильном проявлении данного признака за годы изучения и показывает сравнительно высокую генети- ческую защищенность образцов крамбе в отношении действия гидротермальных факторов.

Наименьшей изменчивостью урожайности за годы исследований отличались образцы к-35, к-34 и к-10, параметры стабильности которых составили 22,8; 26,1 и 29,0 \%. Данные образцы, как в оптимальных условиях выращивания, так и в экстремальных, проявляют толерантность ко всем стрессорам и формирует стабильную урожайность по годам.

Различные генотипы по-разному реагируют на одну и ту же среду обитания, что, в конечном итоге, сказывается на их общей адаптивной способности.

Все сортообразцы, в среднем за годы исследований, показали высокую адаптивность к условиям выращивания, коэффрициент адаптивности варьировал в пределах 0,86-1,13. Наиболее высокие значения данного показателя имели номера к-25, к34, к-39 и к-35, коэффрициент адаптивности которых был больше 1,0 и составил 1,01-1,13, что показывает их большую приспособленность к конкретным условиям (табл. 3).

Таблица 3

Параметры адаптивности сортообразцов крамбе абиссинской (среднее по двум регионам)

\begin{tabular}{|l|l|c|c|c|}
\hline $\begin{array}{c}\text { Cop- } \\
\text { тооб- } \\
\text { разец }\end{array}$ & \multicolumn{1}{|}{$\begin{array}{c}\text { Проис- } \\
\text { хождение }\end{array}$} & $\begin{array}{c}\text { Коэф. } \\
\text { адап- } \\
\text { тивно- } \\
\text { сти }\end{array}$ & $\begin{array}{c}\text { Эколо- } \\
\text { гиеская } \\
\text { устой- } \\
\text { чивость }\end{array}$ & $\begin{array}{c}\text { Пока- } \\
\text { затель } \\
\text { ПУСС }\end{array}$ \\
\hline $\begin{array}{l}\text { Демет- } \\
\text { ра, st }\end{array}$ & Пенза & 0,99 & 0,79 & 0,30 \\
\hline к-25 & Канада & 1,01 & 0,98 & 0,20 \\
\hline к-35 & Германия & 1,13 & 0,75 & 0,41 \\
\hline к-10 & Украина & 0,99 & 0,49 & 0,52 \\
\hline к-7 & Воронеж & 0,86 & 0,64 & 0,32 \\
\hline к-8 & Башкирия & 0,87 & 0,74 & 0,28 \\
\hline к-39 & США & 1,12 & 0,53 & 0,47 \\
\hline к-34 & Чехословакия & 1,04 & 0,86 & 0,32 \\
\hline к-21 & Португалия & 0,99 & 0,93 & 0,23 \\
\hline
\end{tabular}

Оценка образцов по показателю уровня стабильности сорта показала, что высоким значением данного признака отличались сортообразцы к-39 и к-10, ПУСС которых составил 0,47 и 0,52 соответственно.

При этом у данных номеров отмечены низкие значения экологической устойчивости 0,49 и 0,53, что показывает более широкий диапазон их приспособленности к различным условиям произрастания.

Таким образом, оценка сортообразцов крамбе по продуктивности в контрастных гидротермальных условиях Пензенской области и степного Крыма показала, что лучшими номерами были к-35 (Германия), 
к-39 (США) и к-34 (Чехословакия), которые сформировали высокую урожайность 1,872,04 т/га, что превышает сорт-стандарт Деметра на 0,08-0,25 т/га. Данные номера отличались высокими значениями коэффи- циента адаптивности, который составил 1,04-1,13 и показывает их большую приспособленность к различным условиям возделывания.

\section{Лumepamyра}

1. Гужов, Ю. Л. Селекция и семеноводство культивируемых растений/ Ю. Л. Гужов, А. Фукс, П. Величек. - Москва: Мир, 2003. - 536 с.

2. Животков, Л. А. Методика выявления потенциальной продуктивности и адаптивности сортов и селекционных фрорм озимой пшеницы по показателю урожайности / Л. А. Животков, 3. А. Морозова, Л. И. Секутаева // Селекция и семеноводство. - 1994. - № 2. - С. 3-6.

3. Жученко, А. А. Адаптивная система селекции растений (эколого-генетические основы) / А. А. Жученко - Москва: РУДН, 2001. - Т. 1. - 780 с.

4. Зазуля, А. Н. Расширение сырьевых ресурсов для производства биодизельного топлива / А. Н. Зазуля, С. В. Романцова, Е. А. Улюкина // Наука в центральной России. - 2014. - № 4. C. 64-84.

5. Кшникаткина, А. Н. Технология выращивания крамбе абиссинской на семена с использованием микроэлементных удобрений и регуляторов роста / А. Н. Кшникаткина, Д. С Крылова // Вестник Ульяновской государственной сельскохозяйственной академии. - 2016. - № 4 (36). C. $30-38$.

6. Методика проведения полевых агротехнических опытов с масличными культурами / под ред. В. М. Лукомца. - Краснодар, 2010. - 327 с.

7. Неттевич, Э. Д. Потенциал урожайности рекомендованных для возделывания в Центральном районе РФ сортов яровой пшеницы и ячменя и его реализация в условиях производства / Э. Д. Неттевич // Доклады РАСХН. - 2001. - № 3. - С. 50-55.

8. Прахов, В.А. Продуктивность CRAMBE в зависимости от агроприемов возделывания / В. А. Прахов // Инновационные технологии в АПК: теория и практика: сборник материалов конференции. - Пенза, 2017. - С. 104-106.

9. Прахов, В. А. Продуктивность семян крамбе абиссинской в зависимости от густоты посева / В. А. Прахов, М.В.Данилов // Роль вузовской науки в решении проблем АПК: сборник материалов конференции. - Пенза, 2018. - С. 117-121.

10. Прахова, Т. Я. Агроэкологические аспекты формирования агроценозов нетрадиционных масличных культур / Т. Я. Прахова, В. А. Прахов, Е. Л. Турина // Известия Самарского научного центра Российской академии наук - 2018. - Т 20. - № 2-2. - С. 357-362.

11. Сазонкин, К. Д. Крамбе абиссинская: нетрадиционная масличная культура, обладающая большим потенциалом / К.Д. Сазонкин, М. М. Крючков// Приоритетные направления научнотехнологического развития агропромышленного комплекса России: сборник материалов конференции. - Рязань, 2019. - С. 536-541.

12 Canova, E. B. Torta de crambe (Crambe abyssinica Hochst) naalimentacao de cordeiros / E. B. Canova. - Nova Odessa - SP Fevereiro, 2012. - 64 p.

13. Eberhart, S. A. Stability parameters for comparing varieties/ S. A. Eberhart, W. A. Russel // Crop. Sci. - 1966. - № 6. - P. 36-40.

14. Agrobiological Basis For Formation Of Crambe Abyssinica Agrocoenosis In Condition Of Middle Volga/ T. Ya. Prakhova, A. A. Smirnov, V. A. Gushchina, O. N Kukharev // Research Journal of Pharmaceutical, Biological and Chemical Sciences. - 2018. - № 9 (5). - P. 2168-2172.

15. Energy and economic efficiency of Camelina and Crambe biomass production on a large-scale farm in north-eastern Poland / M. J. Stolarski, M. Krzyzaniak, J. Kwiatkowski, J. Tworkowski, S. Szczukowski // Energy. - 2018. - № 150. - P. 770-780.

16. Germination and formation of Crambe seedlings irrigated with saline waters / A. C. F. Vasconcelos, L. H. G. Chaves, F. G. Souza, H. R. Gheyi, J. D. Fernandes // Revista de Ciências Agrárias. 2014. - № 37 (3). - P. 306-311.

17. Effect of row spacing and plant density on grain yield and yield components of Crambe abyssinica Hochst / T. Zoz, F. Steiner, A. Zoz, D. D. Castagnara, T. W. Witt, M. D. Zanotto, D. L. Auld // Ciências Agrarias, Londrina. - 2018. - Vol. 39. - № 1. - P. 393-402. 
UDC 633.85:631:526.32

DOI 10.36461/NP.2020.54.1.006

\title{
EVALUATION OF CRAMBE VARIETY SAMPLES DEPENDING ON HYDROTHERMAL CONDITIONS
}

\author{
T. Ya. Prakhova, Doctor of Agricultural Sciences, Chief Researcher, \\ E. L. Turina*, Candidate of Agricultural Sciences, Head of the Plant Crop Laboratory
}

Federal State Budgetary Scientific Institution «Federal Scientific Center for Bast Crops», Russia, the workers settlement of Lunino, t. +79534479608, e-mail: prakhova.tanya@yandex.ru

*Federal State Budgetary Institution of Science «Research Institute of Agriculture of Crimea», Russia, Simferopol, Republic of Crimea, t. +79788741692, e-mail: turina_e@niishk.ru

The aim of the research was to evaluate the productivity and adaptability of varieties of crambe abyssinica depending on hydrothermal conditions. The object of the research was varieties of various ecological and geographical origin. The study was conducted in contrasting climatic conditions of the Middle Volga and steppe Crimea in 2017-2019. The productivity of varieties of crambe abyssinica varied between 1.54-2.04 t/ha, on average in two regions. On average, for three years a higher yield was observed for samples k-39 (USA) and k-35 (Germany), which productivity was 2.01-2.04 t/ha, which exceeded the standard variety Demetra by 0.22 and 0.25 t/ha. These samples were distinguished by high values of adaptability coefficient, which amounted to 1.04-1.13 and showed their great adaptability to various cultivation conditions. Varieties from Canada (k-25) and Czechoslovakia (k-34) formed yields of 1.82 and $1.87 \mathrm{t} / \mathrm{ha}$, which was slightly higher than the standard for yields. The increase there was 0.03 and $0.08 \mathrm{t} / \mathrm{ha}$. The fat content in fruitlets ranged from 29.68-32.20\%. According to the results of this feature, the number k-35 from Germany was distinguished, the oil content was $32.20 \%$. The most stable yields had the samples k-35, k-34 and k-10, which stability parameters were 22.8; 26.1 and $29.0 \%$. The varieties k-39 and k-10 were distinguished by a high value of the indicator of the variety stability level (IVSL), the values of this trait were 0.47 and 0.52 , respectively. Moreover, these varieties had a high environmental sustainability $(0.49$ and 0.53$)$, which showed a wider range of their adaptability to different growing conditions.

Key words: crambe abyssinica, varieties, yield, adaptability, oil content

\section{References:}

1. Guzhov, Yu. L. Selection and seed production of cultivated plants / Yu. L. Guzhov, A. Fuchs, P. Velichek. - Moscow: Mir, 2003.- 536 p.

2. Zhivotkov, L. A. A technique for identifying the potential productivity and adaptability of varieties and breeding forms of winter wheat by the yield indicator / L. A. Zhivotkov, Z. A. Morozova, L. I. Sekutaeva // Selectsiya i Semenovodstvo. - 1994. - № 2. - p. 3-6.

3. Zhuchenko, A. A. Adaptive system of plant breeding (ecological and genetic basis) / A. A. Zhuchenko - Moscow: RUDN, 2001. - v. 1. - 780 p.

4. Zazulya, A. N. The expansion of raw materials for the production of biodiesel / A. N. Zazulya, S. V. Romantsova, E. A. Ulyukina // Science in Central Russia. - 2014. - № 4. - p. 64-84.

5. Kshnikatkina, A. N. The technology of growing crambe abyssinica for seeds using microelement fertilizers and growth regulators / A. N. Kshnikatkina, D. S. Krylova // Bulletin of Ulyanovsk State Agricultural Academy. - 2016. - № 4 (36). - p. 30-38.

6. Methodology for conducting field agrotechnical experiments with oilseed crops / ed. by V. M. Lukomets. - Krasnodar, 2010.-327 p.

7. Nettevich, E. D. The yield potential of recommended for cultivation in the Central region of the Russian Federation varieties of spring wheat and barley and its implementation in the conditions of production / E. D. Nettevich // Reports of RAAS. - 2001. - № 3. - p. 50-55.

8. Prakhov, V. A. Productivity of CRAMBE depending on agricultural practices of cultivation / V. A. Prakhov // Innovative technologies in agribusiness: theory and practice: a collection of conference materials. - Penza, 2017.- p. 104-106.

9. Prakhov, V.A. Crambe abyssinica seed productivity depending on planting density / V. A. Prakhov, M. V. Danilov // The role of university science in solving agricultural problems: a collection of conference materials. - Penza, 2018.-- p. 117-121.

10. Prakhova, T. Ya. Agroecological aspects of the formation of agrocenoses of non-traditional oilbearing crops / T. Ya. Prakhova, V. A. Prakhov, E. L. Turin // Bulletin of Samara Scientific Center of the Russian Academy of Sciences - 2018. - v. 20. - № 2-2. - p. 357-362. 
11. Sazonkin, K. D. Crambe abyssinica: a non-traditional oil-bearing crop with great potential / K. D. Sazonkin, M. M. Kryuchkov // Priority areas of scientific and technological development of the agro-industrial complex of Russia: a collection of conference materials. - Ryazan, 2019.- p. 536-541.

12 Canova, E. B. Torta de crambe (Crambe abyssinica Hochst) naalimentacao de cordeiros / E. B. Canova. - Nova Odessa - SP Fevereiro, 2012. - 64 p.

13. Eberhart, S. A. Stability parameters for comparing varieties / S. A. Eberhart, W. A. Russel // Crop. Sci. - 1966. - № 6. - p. 36-40.

14. Agrobiological Basis For Formation Of Crambe Abyssinica Agrocoenosis In Condition Of Middle Volga/ T. Ya. Prakhova, A. A. Smirnov, V. A. Gushchina, O. N Kukharev // Research Journal of Pharmaceutical, Biological and Chemical Sciences. - 2018. - № 9 (5). - p. 2168-2172.

15. Energy and economic efficiency of Camelina and Crambe biomass production on a large-scale farm in north-eastern Poland / M. J. Stolarski, M. Krzyzaniak, J. Kwiatkowski, J. Tworkowski, S. Szczukowski // Energy. - 2018. - № 150. - p. 770-780.

16. Germination and formation of Crambe seedlings irrigated with saline waters / A. C. F. Vasconcelos, L. H. G. Chaves, F. G. Souza, H. R. Gheyi, J. D. Fernandes // Revista de Ciências Agrárias. 2014. - № 37 (3). - p. 306-311.

17. Effect of row spacing and plant density on grain yield and yield components of Crambe abyssinica Hochst / T. Zoz, F. Steiner, A. Zoz, D. D. Castagnara, T. W. Witt, M. D. Zanotto, D. L. Auld // Ciências Agrarias, Londrina. - 2018. - vol. 39. - № 1. - p. 393-402. 